\title{
Selling the JUBILEE Project: issues arising from a methodology
}

\author{
Pat Gannon-Leary, Linda Banwell and Sue Childs
}

\section{The authors}

Pat Gannon-Leary is a researcher in the Information Management Research Institute at Northumbria University and was formerly JUBILEE Project Officer. Linda Banwell is the Director of the Information Management Research Institute at Northumbria University. Sue Childs is a researcher in the Information Management Research Institute at Northumbria University.

\begin{abstract}
This article, inspired by JUBILEE project fieldwork, is influenced by van Leeuwen and Leeuw's work on the growing negative attitude towards market research. While the JUBILEE team, as academic researchers, were not making a sales pitch, they were trying to sell the project to putative participants. Issues discussed include length - and degree of difficulty - of questionnaire; how to sell a questionnaire; and how to identify key prospects for interviews and focus groups. Through the experiences gained, the JUBILEE researchers were able to identify key points of good fieldwork practice in relation to the issues discussed.
\end{abstract}

Sex and sentimentality sell...unfortunately we have to work a lot harder Carter Roe (Advertising \& Marketing) - Billboard

This article was inspired by fieldwork undertaken for the JUBILEE project when researchers were confronted with a series of problems in respect of their methodology, especially in connection with getting access to a particular population in order to disseminate questionnaires and arrange interviews and focus groups. The researchers looked critically at the areas of difficulty and at strategies for overcoming them. The article is influenced by the work of Rob van Leeuwen and Edith de Leeuw (1999) entitled I am not selling anything in which they cite recent studies in the Netherlands that indicate a growing negative attitude towards market research. Nearly one quarter of respondents in the work of Brennecke (1998) were convinced that market research was selling under the guise of research. Potential respondents, anticipating a sales-pitch, will not be predisposed to participating in a serious and legitimate survey. This problem is exacerbated when interviews are over the telephone rather than face-to-face since 'phone interviewers have less time to convince respondents of their bona fide intentions. The work of Leeuwen and Leeuw equates the research process with marketing methods. In consequence, the authors reassessed their own experiences in working on an academic research project, when trying to arrange both telephone and face-to-face interviews with members of higher education institutions and in the wider context of the research methods utilised for the project in question, JUBILEE. 
It should be made apparent from the outset that, for a serious piece of academic research, the JUBILEE project team was not making a sales pitch but, on the other hand, we were trying to sell something. In order to gain cooperation from members of HE organisations the team had to convince them there was something for them in the research: in other words, to sell the project to them. As Leeuwen and Leeuw contend,

"Survey characteristics may interact with the efficacy of the 'not-selling' argument. For instance, when the topic is very salient for the respondent the 'not-selling' argument may have far less influence than with a not salient topic. In some studies, it was possible to mention the sponsor (e.g., university, European communion), theoretically these studies hardly needed the non-selling argument"

It was also perceived as advantageous if the organisation carrying out the research had a credible 'image' with the target population. Highly salient topics, as would be expected, result in a higher response, especially when an appropriate population is targeted. A higher response rate is also anticipated when there is a salient 'agency' conducting the research, although Leeuwen and Leeuw found that, for all agencies, a 'not-selling' introduction improved respondent cooperation.

\section{JUBILEE}

JUBILEE (JISC User Behaviour in Information seeking: Longitudinal Evaluation of EIS) is funded by the JISC for three years under its call on Monitoring and Evaluating User Behaviour in Information Seeking and Use of Information Technology and Information Services in UK Higher Education (JISC Circular 1/99). It is investigating Strand D: A Qualitative Longitudinal Monitoring of EIS Use. JUBILEE seeks to predict, monitor and characterise information-seeking behaviour in relation to Electronic Information Services (EIS) and will provide illuminative and contextualised pictures built up over time, in different disciplines. It will focus on users and nonusers in actual sites (fieldwork institutions and Departments within them) and virtual sites (discipline/subject communities). Pictures will be built up using multi-layered user contexts taking account of the individual, the discipline, and the actual or virtual community. The project is designed in three annual cycles of investigation, with each cycle focusing on three disciplines via six case study institutions. Data is being collected and analysed in each cycle, with findings being used to inform subsequent cycles, and to refine the resulting benchmarking tool.

From this brief introduction it can be seen that the JUBILEE project deals with a salient topic as far as the target population is concerned, i.e. EIS as they are being used within HE as seen from the perspective of putative EIS users. However, the population needs to appreciate the saliency of the topic within their particular context: that EIS are useful, effective, efficient, quality, required by lecturers and embedded in assessed work, for example. The 'agency' conducting the research is a team from Northumbria University, an institution from the same sector as those which are being targeted and which therefore should be seen as 'salient'.

\section{Methodology and issues arising}

JUBILEE aims to provide a qualitative longitudinal monitoring of EIS use and the objectives are as follows:

Library and Information Research News 26(83), Summer 2002, pp 27-35 
- to contextualise user interaction with EIS, where EIS is included as part of an holistic view of user information seeking behaviour. This should illuminate both the use and non-use of EIS;

- to use longitudinal tracking of users to determine success criteria for information seeking from the users' points of view;

- to incorporate success criteria into an Action Plan for HE managers;

- to facilitate achievement of the optimum position for an HEI where service providers' expectations of service use meet the reality (as identified by the users) of service use.

To this end the JUBILEE fieldwork included the following survey methods:

- Paper and email questionnaires to academic and LIS/IT staff and students in target disciplines to collect background data on information behaviour, especially in relation to EIS;

- Face-to-face interviews with key informants in disciplines and LIS service personnel at case study sites;

- Face-to-face interviews with other academics in target disciplines snowballed by LIS staff and other academics;

- Focus groups with staff and students in target disciplines.

In addition to being influenced by saliency of topic, type of population and respondent selection, the overall degree of cooperation in respect of the research may be influenced by survey burden. When an interview is long or has difficult questions interviewers may be more reluctant or hesitant in their introduction (cf. Groves \& Couper, 1998, p. 289). While the duration of an interview was found to influence response, Leeuwen and Leeuw found no such negative influence from cognitive burden (i.e. degree of difficulty of questioning). There have been mixed findings in respect of the benefits of conveying reassurance to respondents in an advance letter. Some research indicates an increase in response (Heberlein \& Baumgartner, 1978 and Lynn et al, 1997); some a negative (Groves \& Couper, 1998); some indicate a dependency on content and length of the letter (Dillman, Gallegos, \& Frey, 1976; Lynn, Turner, \& Smith, 1997).

\section{Selling the questionnaires}

Projects that seek student responses commonly find it hard to 'sell' questionnaires, and JUBILEE is no exception. The project team had expected difficulties, and therefore put in place from the outset a flexible and varied set of techniques for making contact with students, with the work undertaken by experienced, confident and persistent researchers. Each site had different local formalities: e-mail questionnaires to students were permissible in some places, with student addresses supplied to the researcher, or with mediating assistance from a departmental administrator. Some sites had student pigeonholes where paper copies of questionnaires could be left. Some departments had their own common rooms where the researcher could contact students direct with a few brief and well-chosen questions. Without doubt, the most effective way of contacting students was through willing academics, who were interested in the topic being investigated and so lent their support to the project. This sometimes meant the researcher gained access to the students for five minutes at the end of a lecture; or on some occasions 
lecturers distributed questionnaires and collected them in again; or even arranged a focus group of students. The key contact for the researcher at the site was generally the individual who mediated with the academics, and was therefore of crucial importance in planning and facilitating data collection on-site.

\section{Length of questionnaire}

Questionnaires should, ideally, be brief and concise. The JUBILEE questionnaire extended to five sides of A4, although much of this was in the form of tickboxes so did not require much effort on the part of the respondent. However, the project team acknowledge that the questionnaire length may have been off-putting to some of the target population. While only two or three respondents said it was overlong to complete, many more may have 'voted with their feet' either by completing only the tickbox sections, not the free text, or by not completing the questionnaire at all.

\section{Degree of difficulty}

The degree of difficulty of the questions in the JUBILEE instrument was variable. As mentioned above, the project team used mediators - key contacts in LIS, academics, and administrators - to help gain access to the target population. In so doing, much depended on the degree of enthusiasm with which such individuals 'sold' the project to their colleagues. There were problems in respect of cognitive burden. Some contact personnel had been press-ganged into participating by their Head of Department (HoD) and were not wholly committed to the project. The concept of Electronic Information Services was foreign to many and in consequence the project team experienced negative attitudes - and in some cases hostility - from some interviewees. The acronym JUBILEE incorporates the name of the funding body, the JISC, and one of the questions asked of key informants involved finding out how much they knew about the JISC and it's activities. In many instances, this proved to be very little so the team had to sell not only the project but also the funder, the services and the technology!

\section{The advance 'letter'}

Because much of the JUBILEE fieldwork was conducted at case study sites at a distance from Northumbria, the research team implemented a plan of action. Prospecting for clients was facilitated by the fact that Northumbria had a good track record in Information Services research, e.g. in the IMPEL research, and had well-established relationships with Heads of LIS in several academic institutions.

As Yin (1988) points out, preparation of a research protocol alerts researchers to potential problems. Preparation of the action plan focussed the team's minds on hoped-for outcomes and on the best approach to their achievement. Initial contact was made by telephone and, once the Project Manager had received agreement from Heads of LIS to participate in the research, the contact person (nominated by their HoD) was sent this plan. The plan explained the project in detail; the disciplines under investigation; the degree of involvement $\mathrm{s} /$ he would experience (the action plan stressed that this was minimal); research methods which would be employed and the aims of each; and an indicative timetable for a week's worth of fieldwork. 
In addition to this plan, the JUBILEE team had produced flyers about the project, which were provided to the contacts along with copies of the covering letter for the questionnaire. Some of the contact personnel at sites used the action plans and flyers as promotional material for the project within their institutions, e.g. to sell the idea to academics whom they wished to participate or as copy for institutional newsletters.

\section{Identifying key prospects for interview}

Successful selling involves identifying key prospects and this was occasionally problematic for the JUBILEE team. As stated above the 'agency' (Northumbria) had a reputation for research in EIS; had good previous working relationships with HoDs; and, consequently, commitment from them. However, the HoDs were required to suggest contacts with whom the project team could work and sometimes those suggested were not the most appropriate, lacking interest in - and enthusiasm for - the project. This applied both to staff within the library and those in academic departments.

The LIS staff asked to give contact people in subject areas were not always the most appropriate ones to do so. Much depended on the sort of relationships they themselves had with the academics. Some liaison personnel had built up good communications with their academics and were able to sell the project on the team's behalf. Others had very poor relationships, had not built up a rapport with academics and were unable to convince them of the worthwhile nature of the project. Sometimes this led to antipathy on the part of the academics, which made it very difficult for the JUBILEE team who had to be aware of negative signals being sent out and redress the balance in order to secure appointments. Contacts were concerned about the amount of time involved in helping the JUBILEE researcher even though the team had stressed this would be minimal - really an 'entrée' was all that was required and, once introduced, the researcher would take over the sale of the project herself. Once she had a 'foot in the door', a cascading/snowballing method, by which at the end of an interview she asked, "Is there anyone else you think I should talk to?" - proved effective. Sometimes the interviewee actually introduced the researcher to a nominated person. The researcher's work was facilitated by being able to "phone the nominee and say, "Dr. X" suggested you might be a good person to speak with about this project." This ethical version of pyramid selling proved fruitful, as did asking academic interviewees if they had a group of students in the near future to whom they could distribute some questionnaires. If questionnaires had already been distributed to students, it was found worthwhile to ask academics interviewed to encourage their students to complete these.

\section{Identifying key prospects for focus groups}

As well as identifying key prospects for interview, sometimes the LIS and academic contacts were able to identify those for focus groups. Holding a focus group with LIS staff early on in the project was helpful. This fulfilled a similar function to the early stages of a sales call, in that it enabled the researcher to give an effective informal 'presentation' using appropriate language so that she made a favourable impression on them. It also ensured they had sufficient knowledge about the project to help target interviewees, and it helped keep the project moving forward.

The questionnaires were mailed to distant sites in advance of the fieldwork visit. In some cases the research team were able to get these distributed prior to the fieldwork period. In such 
instances, a volunteer sheet was attached to the questionnaire. This gave respondents the opportunity to volunteer to be interviewed (in person, by 'phone or by e-mail) or to participate in a focus group. From returns the research team were able to generate lists of volunteers before the fieldwork and this facilitated setting priorities and time management since dates, times and venues for individual and group interviews could be arranged in advance. Where focus groups had to be arranged while the researcher was on site, two effective selling methods were deployed. Firstly, if academics were teaching a 'Research Methods' module then having their students participate in a focus group would afford them an opportunity to experience this particular method at first hand. Secondly, if academics were incorporating EIS into the curriculum, having the researcher discuss EIS with the students during the group interview would reinforce their teaching. During the focus group sessions members of the project team had to ensure that good interview techniques were employed so that the agency was represented professionally - e.g., asking open questions, listening to what 'customers' were actually saying, not making assumptions - skills applicable to both researchers and sales personnel.

With questionnaires, researchers feel in control to the extent that they have devised the questions and receive the responses in the order in which they anticipate them and confined to a set of delineated boxes. Of course, the choice as to whether or not to fill in the questionnaires does reside with the subjects. However, with interviews the researchers relinquish a certain amount of control and have to be equipped to cope with this change of circumstance. As Yin says, the JUBILEE researchers had to "learn to integrate real-world events with the needs of the data collection plan" (Yin, 1988, p.73). Such integration involves adapting to the interviewee's timetable, availability and geographical location since it is that interviewee's 'real world' which the researcher is entering. The JUBILEE team learned to adopt coping strategies to handle such situations where an interviewee may be as negative or hostile as the householder confronted by a 'foot in the door' sales representative.

Through the experiences gained, the JUBILEE researchers were able to identify key points of good fieldwork practice:

\section{Devising good fieldwork practice based on JUBILEE experiences}

\section{Key prospects}

- In disciplines with very large student numbers, such as Business Studies, it will probably not be possible to send out questionnaires to all students; a sample is permissible, provided that it includes all types of student (full time, part time, distance etc.);

- Some areas of some target disciplines fall into other schools (e.g. In the case of Health, Psychology and Human Biology taught in the school of Science) and your contact people will be aware of such anomalies/inconsistencies;

- LIS do not necessarily have the most up-to-date or appropriate information about departments and contacts, and time has been wasted. Researchers need to be more pro-active themselves in contacting Departments, with appropriate permissions; snowballing from one contact to the next etc; 
- Contact students via departmental clubs, Students' Unions, in departmental libraries, common rooms, workrooms with PCs in, canteens and cafeterias;

- Advertise via questionnaire flyers; mailshots; posters; newsletters.

\section{Selling the questionnaire}

- Re-visit the JUBILEE questionnaire critically and shorten it overall in the interests of improving response rates. Use this shorter but comprehensive version for all target disciplines. Make it available as hard copy and as text for insertion in an e-mail message.

- E-mail questionnaires with the questions delivered as a text message are generally easier for respondents to cope with and therefore preferable to other forms, such as an attachment;

- Ideally global mailing lists need to be available by discipline rather than just by school to capture required population;

- Success of e-mail version is dependent on how well used is email in the institutional culture;

- Produce an even shorter mini-version questionnaire on card for insertion where possible in library book issues or via. Students' Union newsletters. This version should help include non-users as well as users of EIS.

- Consider book token/WHSmith token prize to encourage student response;

- Sometimes you end up sending a load of individually enveloped questionnaires to the same institution with only the student name differing. Bulk mailings are problematic unless the institution has adequate facilities to distribute them from a Post Room or similar. Such a parcel may be opened by the Portering staff and it is uncertain how effectively the individual questionnaires will be distributed.

\section{Timing and getting appointments}

- Some university websites contain almanac with details of semesters, exam timetables etc. work around these. Eschew school holidays, which mean childcare problems and fewer people around.

- Also avoid independent learning weeks, work placement periods etc. when students will be off-site;

- Make more use of telephone interviews, which can be undertaken at any time and are not confined to the time when the researcher is on-site;

- A very long lead-time is required to establish contacts and channels of communication at the site and to allow departments to plan student participation; flexibility is essential. It is seldom possible to parcel the fieldwork at a site neatly into the week the researcher happens to be there. It is to the project's advantage to be flexible, which places a high value on the organisational skills of the researchers, who will almost certainly be undertaking fieldwork at several sites at the same time.

- The optimum time for fieldwork seems to be the Spring Term from all points of view, although it is clearly not possible to compress it all into this timespan.

\section{Market research in advance of research design: some discussion}

Assembling participants for a research project is not normally achieved by the use of marketing techniques. Volunteers are sought and the research team hopes for the best. The extent to which 
recruitment succeeds often has more to do with external factors (e.g. whether they perceive the project to be of interest or benefit to them) than with anything the researchers have done.

Groups covered for the JUBILEE project included:

- LIS/IT staff

- Academic staff

- Students

On the whole the research team expected that LIS staff would be keen to participate as the research is in their domain and the results could be of direct benefit to them. If the project happens to coincide with a monitoring activity then it can increase LIS willingness to be involved. However such willingness is not found in all cases. This raises questions as to reasons for the lack of enthusiasm. Some reasons could be survey fatigue, pressure of work, or staffing constraints. There may be less obvious local factors or internal political issues. One selling strategy for LIS would be to feed back results for them to use for in-house monitoring or as a guide to good practice. A similar approach would seem to be appropriate for IT staff, with more of a spin on the IT aspects.

Since EIS are crucial to teaching and learning, the JUBILEE team hoped that academic staff would be interested in the project and see benefits to themselves. The academics at some case study sites were either under enormous time pressures or did not see that LIS had anything to offer to their role. This came across quite strongly with some of the departments which viewed academics as pre-eminent and support services as having an almost servile role to play. This also partially explains academics taking on the role of EIS development themselves since they fail to see any value in working in partnership with LIS and IT and do not credit these services with any strengths to bring to such a partnership. In addition, there were a number of examples at sites that demonstrated that LIS staff seemed unaware of the best people to contact with the organisation and were not 'in the loop.' In such a case selling would appear to need to be done directly, by approaching the academics themselves.

Making an approach through the HoD did not always prove fruitful since, if s/he lacked interest, the researcher fell at the first hurdle. Cascading it through the academics appeared to have some potential. The biggest concern seemed to be time so the most appropriate selling point might be as a way of facilitating keeping up to date with new developments. This was highlighted as a good practice pointer. JISC did not prove to be a selling point because the everyday academic did not relate to JISC, did not know much of its work and therefore did not see the relevance. Often, if any organisation solicits consultancy based research employees are obliged to participate. JISC does not have this relationship to HEIs. Nor does the academic culture with its ethos of independence lend itself to the big stick approach. It's more likely to have a negative effect. VCs and Heads of Departments might be able to persuade, but they certainly wouldn't / couldn't demand participation.

One point worth making in connection with JUBILEE, is that such research is much more constrained by ethics than market research is. The team needed to consider not only the ethical

Library and Information Research News 26(83), Summer 2002, pp 27-35 
aspect of the research but also the need not to offend because of its effect on the reputation of the organisation conducting the research and the possible spin-off effects on the LIS personnel at case study sites. Such constraints required that the researchers went through the 'proper' channels rather than just keeping contacting people within institutions until some were found who were prepared to participate. The Data Protection Act also affected the research team's ability to send flyers or questionnaires directly to people within the case study institutions.

Student groups are practically impenetrable. A cynical generalisation might be that they will not do anything more than the bare minimum, and nothing at all unless it contributes to their assessment! Obviously this is a sweeping generalisation and there are some interested students but how, from the large number of students, does the researcher identify them? An introduction through the academics is ideal but this requires two things:

(i) the need to get to the academics first, so it's a second stage in the selling process;

(ii) that academics motivate students to participate.

Some academics in the JUBILEE case studies organised the distribution of questionnaires to large numbers of students. However, because this was a purely administrative involvement students were not enthused and, in consequence, few responded.

The JUBILEE team may need to examine ways of disseminating questionnaires in the guise of a teaching exercise. For example:

(i) involving students in some research activity, even as participants, helps them learn about research. This might involve the research team's preparedness to be critiqued on their methodology;

(ii) getting students to think about EIS use as a way of increasing their uptake and skills.

Some personnel at case study sites expressed the opinion that students wouldn't do anything unless they were paid. But interestingly this view was expressed in a department at one case study site from which the research team got a good response. The downsides from the JUBILEE project viewpoint would be:

(i) the cost and what would be deemed a 'reasonable' amount and would a research funding body accept this in-built as part of the bid?

(ii) The possibility of biasing the results in some way, e.g. who decided to respond, or would respondents try to answer in ways they thought would please the project team

The idea of a lottery approach (number questionnaires, put into a hat, winner receives a prize) would also be affected by the same issues of degree of success, cost, and bias. An additional problem would be that confidentiality would be broken down and therefore have ethical implications - even a concern about breaching gaming laws!

The comments on the different target groups above have been made as if these groups were homogenous but, of course, they are not. The researchers also have to give consideration to the Library and Information Research News 26(83), Summer 2002, pp 27-35 
different subject areas in which academic staff are operating. They then need to look for ways to increase motivation to respond to JUBILEE through those subject needs and/or to work on the level of development they have reached with regard to their own IT skills and EIS awareness. While student target groups are also divisible by subject, probably more important is their mode of attendance, e.g. full-time, part-time, distance learning (DL). While handing out questionnaires before or after lecture slots, with academics' agreement, might be a suitable strategy for targeting full-time students it is likely to be less effective with part-timers with greater time pressures. If consideration were given to targeting them with questionnaires in their work place, this introduces another factor into the equation. The project might be sold to them by demonstrating that it would help them manage their work or study better. For distance learners, an approach might be through DL techniques, e.g. entry into their email discussion groups or managed learning environment but, again, this would require the cooperation of the academic staff responsible for DL delivery. Consideration was given to distributing questionnaires in Student Unions but a subject-approach, e.g. via student societies, might be successful in reaching specific groups.

\section{Selling opportunities for JUBILEE}

Like sales representatives, the JUBILEE researchers have found a need to be prepared to turn opportunities into 'sales' using proven techniques. In addition they have learned further techniques which they hope will open up greater opportunities to sell the JUBILEE project. The JUBILEE equivalent of clinching deals and generating customer satisfaction has been the dissemination of the results, copies of which went to JISC as funders but also to the Head of LIS in each case study site. Sharing the findings in this way should provide compensating benefits for any inconvenience caused to case study institutions. Hopefully the JUBILEE project team has also built up the kind of client relationship that will lead to future 'sales' with host sites expressing a willingness to participate in similar future research which might afford them a longitudinal perspective. The project team feels that this is indicative of their ability to spot 'buying signals' and to continue to sell the project after the initial 'deal' has been done. It is also demonstrative of the development of a trusting relationship and the team welcomes the opportunity afforded to return to sites and, in effect, provide 'after sales' service to former 'customers'. One stated outcome of the JUBILEE project is a benchmarking and evaluation toolkit for HE managers and such continuing liaison is likely to benefit the creation of a good practice guide.

\section{Bibliography}

(1985) “AMA Board approves new marketing definition,” Marketing News, March 1.

Brennecke, S. (1998). Voorlichting over marktonderzoek blijft nodig [In Dutch: The necessity of correct information on market research]. Memorandum "Uw Mening Telt", April 1998.

Dillman, D.A., Gallegos, J.G., \& Frey, J.H. (1976). Reducing refusal rates for telephone interviews. Public Opinion Quarterly, 40, 66-78.

Library and Information Research News 26(83), Summer 2002, pp 27-35 
Gronroos, C. (1994) From marketing mix to relationship marketing: towards a paradigm shift in marketing. Management Decision, 32, 2, 4-20.

Groves, R.M., \& Couper, M.P. (1998). Nonresponse in household interview surveys. New York, Wiley.

Heberlein, T.A., \& Baumgartner, R.M. (1978). Factors affecting response rates to mailed questionnaires: A quantitative analysis of the published literature. American Sociological Review, 43, 447-462.

IMPEL2 project - IMpact on People of Electronic Libraries. http://ilm.ac.uk/impel

Kotler, P. (1994) Marketing management: analysis, planning, implementation and control. $8^{\text {th }}$ ed. London, Prentice-Hall.

Leeuwen, R. van and Leeuw, E.D. de (1999). I am not selling anything: experiments in telephone introductions International Conference on Survey Nonresponse,

http://www.jpsm.umd.edu/icsn/papers/Deleeuw.htm

Lynn, P., Turner, R., Smith, P. (1997). The effect of complexity and tone of an advance letter on response to an interview survey. Survey Methods Centre Newsletter, 17, 13-17.

Peters, T. (1995) The pursuit of Wow! Every person's guide to topsy-turvy times. Basingstoke, Macmillan.

Webber, S. Marketing library and information services. February 2000

http://www.dis.strath.ac.uk/people/sheila/marketing

Yin, R.K. (1988) Case study research: design and methods. Rev.ed. London, Sage.

WORD COUNT 5,159

Library and Information Research News 26(83), Summer 2002, pp 27-35 